\title{
Cisplatin-Based Chemotherapy for Pulmonary Metastasized Germ Cell Tumors of the Testis - Be Aware of Acute Respiratory Distress Syndrome
}

\author{
Stefan Boeck $^{\mathrm{a}} \quad$ Klaus H. Metzeler ${ }^{\mathrm{a}} \quad$ Andreas Hausmann $^{\mathrm{a}} \quad$ Anja Baumann ${ }^{\mathrm{a}} \quad$ Eike Gallmeier $^{\mathrm{b}}$ \\ Klaus G. Parhofer ${ }^{\mathrm{b}}$ Hans-Joachim Stemmler ${ }^{\mathrm{a}}$ \\ aDepartment of Internal Medicine III, \\ ${ }^{b}$ Department of Internal Medicine II, Klinikum Grosshadern, Ludwig-Maximilians-University of Munich, Germany
}

Key Words

Acute respiratory distress syndrome - ARDS .

Chemotherapy · Cisplatin · Germ cell tumor

\section{Summary}

Background: Cisplatin-based combination chemotherapy is regarded as standard of care for patients with advanced germ cell tumors. In patients with lung metastases and a high tumor load, an association between induction chemotherapy and the development of a 'tumorassociated' acute respiratory distress syndrome (ARDS) has been hypothesized. Case Report: We report the clinical course of a 19-year-old patient who rapidly developed fatal ARDS during the first cycle of chemotherapy using the $\mathrm{PEI}$ regimen (cisplatin, etoposide and ifosfamide) for a metastasized (lung, liver, lymph nodes) germ cell tumor of the testis. Conclusion: Further clinical research in order to better define risk factors for developing ARDS in this patient population as well as novel strategies for the prevention and treatment of ARDS in those patients are necessary.

\section{Introduction}

Since the introduction of cisplatin, platin-based combination chemotherapy has evolved as a standard of care for patients with advanced germ cell cancers [1,2]. Most of these - often young and otherwise healthy - patients can be cured, even if distant metastases already have occurred. However, for
Schlüsselwörter

ARDS (acute respiratory distress syndrome). Chemotherapie $\cdot$ Cisplatin $\cdot$ Keimzelltumor

\section{Zusammenfassung}

Hintergrund: Die Cisplatin-basierte Kombinationschemotherapie wird aktuell als Standardtherapie für Patienten mit fortgeschrittenen Keimzelltumoren betrachtet. Vorangehende Studien zeigten auf, dass bei Patienten mit einer ausgedehnten Lungenmetastasierung eine mögliche Assoziation zwischen einer Induktionschemotherapie und der Entwicklung eines sogenannten "Tumorassoziierten" ARDS (acute respiratory distress syndrome) bestehen könnte. Fallbericht: Wir berichten über die Kasuistik eines 19-jährigen Patienten mit metastasiertem Keimzelltumor des Hodens (Leber-, Lungen-, Lymphknotenfiliae), der bereits während des ersten Zyklus einer Chemotherapie mit dem PEl-Regime (Cisplatin, Etoposid, Ifosfamid) rasch ein letales ARDS entwickelte. Schlussfolgerung: Die zukünftige klinische Forschung sollte versuchen, Risikofaktoren für die Entwicklung eines ARDS in dieser Patientenpopulation zu definieren und zudem auch innovative Strategien zur Prävention und Therapie dieser ARDS-Sonderform zu implementieren.

patients with poor prognostic features, e.g. those within the 'poor-risk' subgroup according to the International Germ Cell Cancer Collaborative Group (IGCCCG), the 5-year survival rate is still about $50 \%$ only. To date, only case reports or small retrospective single-center case series (e.g. from the 'Institut Gustave Roussy') have reported a 'tumor-associated' acute respiratory distress syndrome (ARDS) in patients with non-

\section{KARGER}

Fax +497614520714

Information@Karger.de

www.karger.com (c) 2009 S. Karger GmbH, Freiburg

Accessible online at:

www.karger.com/onk 
seminomatous germ cell tumors and lung metastases [3-5]. Some authors also hypothesized a possible aggravation of acute pulmonary failure by chemotherapy-induced/-associated inflammatory processes and tumor lysis [5]. Currently, no evidence-based prevention concepts or specific treatment options are defined for such a high-risk subgroup of patients who are at risk for developing ARDS after initiation of systemic cisplatin-based chemotherapy [2].

\section{Case Report}

This case report presents a 19 -year-old male patient with a metastatic non-seminomatous germ cell tumor of the testis, who was admitted to our center in April 2008 for treatment initiation. In his history, the patient underwent cardiac surgery at birth (1988) for a transposition of the great arteries according to the Senning-Brom repair. A swelling of the left testis was noticed by the patient in April 2007, but at that time he did not seek medical advice. The admission to a local hospital was finally initiated by his general practitioner due to chest and abdominal pain. Laboratory analysis showed an elevated lactate dehydogenase (LDH) level (1331 $\mathrm{U} / 1)$, together with a considerable elevation of $\beta$-human chorionic gonadotropin $(\beta-\mathrm{HCG})(660,000 \mathrm{mIU} / \mathrm{ml}) . \alpha$-Fetoprotein (AFP) levels were found to be within the reference range $(2.4 \mathrm{ng} / \mathrm{ml})$. An observed latent hyperthyroidism was possibly associated with the significant elevation of $\beta$-HCG levels [6].

The first staging computed tomography (CT) scan showed a diffuse nodular infiltration in the lungs (fig. 1), the liver and the abdominal lymph nodes, and some of the masses showed radiographic signs of necrosis. At presentation, the clinical pulmonary function of the patient was stable (no dyspnea, $\mathrm{SO}_{2}$ without oxygen $96 \%$ ), and thus a left-sided inguinal orchiectomy was performed on the day of admission; the next day (about $18 \mathrm{~h}$ later), systemic chemotherapy using the PEI regimen (cisplatin, etoposide, ifosfamide) was initiated [1,2]. Due to the massive tumor infiltration of the lung, no bleomycin was included in the combination chemotherapy regimen [2]. The final diagnosis was a stage III C (according to the American Joint Committee on Cancer (AJCC) classification) nonseminomatous germ cell cancer of the left testis. Histologically and immunohistologically, the resected specimen (diameter $14 \mathrm{~cm}$ ) showed a mixed germ cell tumor with predominant features of chorion carcinoma but also with features of mature teratoma. According to the IGCCCG classification, the patient was allocated to the 'poor-risk' prognostic subgroup.

Only 2 days after initiation of chemotherapy, the patient rapidly developed a partial respiratory insufficiency together with hemoptysis and was therefore admitted to the intensive-care unit (ICU). On ICU admission, the patient showed an $\mathrm{S}_{2} \mathrm{O}_{2}$ of $92 \%$ at an oxygen flow rate of $9 \mathrm{l} / \mathrm{min}$ via face mask, the blood pressure was $140 / 55 \mathrm{~mm} \mathrm{Hg}$, and the heart rate was $64 / \mathrm{min}$. At that time point, the patient was afebrile, showed only mild elevation of C-reactive protein (CRP) levels $(3.7 \mathrm{mg} / \mathrm{dl}$, reference range $<0.5 \mathrm{mg} / \mathrm{dl}$ ) and an interleukin (IL)-6 level of $<2.0 \mathrm{pg} / \mathrm{ml}$. Immediate empiric antibiotic treatment with piperacillin and tazobactam was begun. We initiated non-invasive continuous positive airway pressure (CPAP) ventilation, but due to respiratory exhaustion the patient had to be intubated 1 day after ICU admission. Chest X-ray showed diffuse infiltrates over both lungs, which were interpreted as lung metastases, possibly also accompanied by pulmonary lymphangiosis carcinomatosa. A bronchoalveolar lavage after intubation showed no typical signs of infection or of active pulmonary bleeding; a broad diagnostic microbiological screening was negative for bacteriology, mycology and virology (testing for herpes simplex virus (HSV), varicella zoster virus (VZV), cytomegalovirus (CMV) and adenovirus). Repeated aspergillus galactomannan antigen tests were negative. While the patient was receiving mechanical ventila-

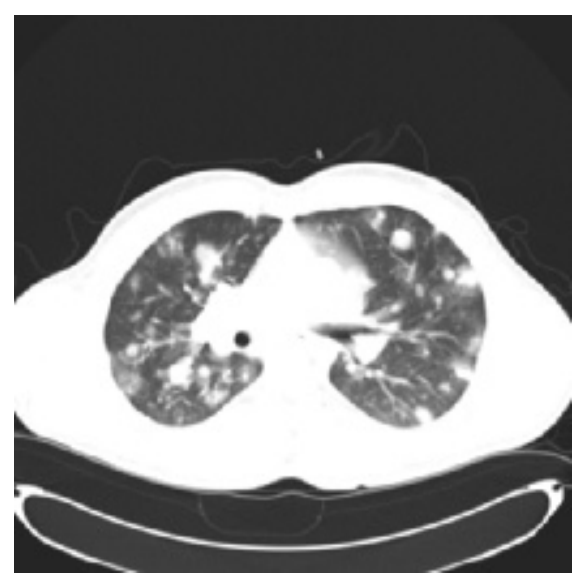

Fig. 1. Bilateral lung metastases on a staging CT scan of the chest performed before the start of PEI chemotherapy.

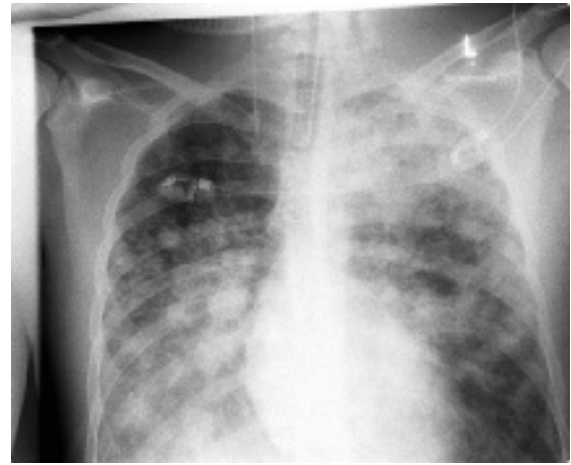

Fig. 2. Chest $X$-ray with signs of ARDS ('white lung') 2 days ante mortem.

tion, we subsequently completed the first cycle of systemic chemotherapy, and no clinical or laboratory sings of a tumor lysis syndrome occurred. 1 day after completion of PEI, the patient developed fever up to $40{ }^{\circ} \mathrm{C}$ and a rise in CRP levels (up to a maximum of $31 \mathrm{mg} / \mathrm{dl}$ ) was observed. Corresponding IL-6 levels rose up to a maximum of $713 \mathrm{pg} / \mathrm{ml}$; the procalcitonin level was $0.9 \mathrm{ng} / \mathrm{ml}$ (reference range $<0.5 \mathrm{ng} / \mathrm{ml}$ ). Parallel to the development of fever, the patient rapidly required a maximally invasive mechanical ventilation (positive end-expiratory pressure (PEEP) levels up to $22 \mathrm{~cm} \mathrm{H}_{2} \mathrm{O}, \mathrm{F}_{\mathrm{i}} \mathrm{O}_{2} 100 \%$ ) in order to achieve a $\mathrm{p}_{\mathrm{a}} \mathrm{O}_{2}>60 \mathrm{~mm}$ $\mathrm{Hg}$. Clinically, the diagnosis of an ARDS was made although the typical radiological signs of ARDS were not present, most probably due to the pre-existing lung metastases (fig. 2). The patient showed no signs of sepsis (low procalcitonin levels, normal coagulation parameters, no severe impairment in renal and hepatic function); thus, an extrapulmonary etiology for the ARDS was rather unlikely. A ventilator-associated pneumonia was ruled out due to negative microbiological findings on broncho-alveolar lavage. Nevertheless, the antibiotic treatment was empirically changed to meropenem, vancomycin, caspofungin and aciclovir. Invasive hemodynamic monitoring - with the use of a transpulmonary thermodilution technique $\left(\mathrm{PiCCO}^{\circledR}\right.$ technology; Pulsion Medical Systems, Munich, Germany) - found a cardiac index (CI) of $3.51 / \mathrm{min} / \mathrm{m}^{2}$ (reference range 3.0$5.0 \mathrm{l} / \mathrm{min} / \mathrm{m}^{2}$ ), a systemic vascular resistance index (SVRI) of about 1800 dyn $\cdot \mathrm{s} \cdot \mathrm{cm}^{-5} \cdot \mathrm{m}^{2}\left(1700-2400 \mathrm{dyn} \cdot \mathrm{s} \cdot \mathrm{cm}^{-5} \cdot \mathrm{m}^{2}\right)$ and an extravascular lung water index (ELWI) of $18 \mathrm{ml} / \mathrm{kg}(3.0-7.0 \mathrm{ml} / \mathrm{kg})$. The ELWI subsequently rose up to a maximum of $30 \mathrm{ml} / \mathrm{kg}$ on the day before the death of the patient. Despite the use of a lung-protective biphasic positive airway pressure $\left(\right.$ BIPAP $^{\circledR}$ ) ventilation, the ARDS remained unresolved and the patient developed severe hypoxemia within a few days only $\left(\mathrm{pO}_{2} 44 \mathrm{~mm} \mathrm{Hg}\right.$ under inverse-ratio ventilation with $\mathrm{F}_{\mathrm{i}} \mathrm{O}_{2} 100 \%$ and PEEP $22 \mathrm{~cm} \mathrm{H}_{2} \mathrm{O}$ ). Additional high-dose steroid treatment at a dosage of $2 \times 1000 \mathrm{mg}$ prednisolone had no positive effect on the ongoing respiratory failure. The use of a pre-emptive continuous veno-venous large-volume hemofiltra- 
tion (initiated in order to achieve a negative volume balance and possibly remove pro-inflammatory cytokines) also had no effect on the progression of ARDS.

10 days after initiation of chemotherapy, the $\beta$-HCG level increased up to $858,000 \mathrm{mIU} / \mathrm{ml}$ (without laboratory signs of a tumor lysis syndrome). Assuming an expected median half-life for $\beta$-HCG of about 3 days [7], we thus furthermore observed no early biochemical treatment response. In this context, and based on the underlying malignant disease as well as the rapid progression and therapy resistance of the ARDS, we decided not to use an extracorporeal lung assist (e.g. extracorporeal membrane oxygenation, ECMO) in our patient. He died 10 days after ICU admission due to refractory hypoxemia caused by a 'tumor-associated' ARDS, possibly aggravated by a chemotherapy-associated inflammatory process.

\section{Discussion}

In 1990, a first case report of a 'tumor-associated' ARDS in a 32-year old patient with pulmonary metastasized chorion carcinoma of the testis was published by McGowan and colleagues [3]. 4 years later, a group from the 'Institut Gustave Roussy' published the first retrospective case series of 11 patients with - what they called - 'super-high-risk germ-cell tumors'; all of these patients suffered from non-seminomatous germ cell cancers and had a high tumor load in the lungs or the mediastinum [4]. Each of these 11 patients experienced ARDS during chemotherapy and required mechanical ventilation; nevertheless, all patients died rapidly within 35 days from the start of chemotherapy. The authors of this case series hypothesized a multifactorial etiology (consisting of bulky disease of the chest, secondary infections and interstitial pulmonary fibrosis) for the acute pulmonary failure observed in their patients [4].

To date, it remains unclear whether chemotherapy-associated processes may also be involved in the pathogenesis of these 'tumor-associated' ARDS cases. A recent case series from Kirch et al. [5] reported 16 patients with non-seminomatous germ cell tumors and lung metastases who were admitted to the ICU for respiratory distress. In this patient cohort, 9 patients $(56 \%)$ developed ARDS requiring mechanical ventilation within a median of 2.5 days only after the initiation of chemotherapy. All but one of the patients requiring invasive ventilation died; none of these patients had received a bleomycin-containing regimen. The only predictor of intubation in this patient population was the initial $\mathrm{p}_{\mathrm{a}} \mathrm{O}_{2}$ on room air upon ICU admission (with all patients having a $\mathrm{p}_{\mathrm{a}} \mathrm{O}_{2}<70 \mathrm{~mm} \mathrm{Hg}$ subsequently developing fatal ARDS). The authors of this small retrospective study concluded that not only the high pulmonary tumor load represents a major factor in the ARDS pathogenesis, but possibly an aggravation of the respiratory failure is - also with regard to the correlation in time - chemo- therapy associated. Chemotherapy-induced inflammation and local tumor lysis could result in an enormous cell death and a high release of cytokines that would ultimately result in an ARDS at the organ level.

In the patient reported here, we also observed a clear correlation between the start of chemotherapy and the development of respiratory distress requiring intubation only 3 days after initiation of treatment (using the non-bleomycin-containing chemotherapy regimen PEI). Despite maximal treatment efforts, the patient died due to progressive ARDS and subsequent hypoxemia.

Based on the data discussed above, a certain subgroup of germ cell tumor patients with lung metastases - those who require intubation and mechanical ventilation - may have a dismal prognosis. Thus, prevention strategies are urgently needed in order to improve the outcome and to avoid the development of ARDS in these patients. A possible new approach could be the introduction of a low-dose or short-course, 'pre-phase' chemotherapy protocol for such a high-risk subgroup, for example analogous to the current standard of care for patients with aggressive non-Hodgkin's lymphoma and a high tumor load [8]. Such an approach was presented by Fizazi and colleagues at the American Society of Clinical Oncology (ASCO) meeting in 2007: Their small retrospective single-center study included 25 patients with lung metastases from non-seminomatous germ cell cancer and dyspnea or a $\mathrm{p}_{\mathrm{a}} \mathrm{O}_{2}<80 \mathrm{~mm} \mathrm{Hg}$ who were treated between 1980 and 2006 at their institution [9]. The subgroup of patients that received initial chemotherapy with a 'full-dose' chemotherapy regimen (1980-1997, n $=15$ ) showed an ARDS incidence of $87 \%$ and a 'long-term survival rate' of 27\%. In contrast, patients treated after 1997 received initial chemotherapy with a 3-day reduced induction regimen of etoposide and cisplatin; in this population $(\mathrm{n}=10)$ the ARDS incidence was $30 \%$, and $40 \%$ of the patients were long-term survivors. However, mostly due to the lack of prospective data from well-defined controlled clinical trials, the current European Germ Cell Cancer Consensus Group (EGCCCG) guidelines only recommend that '...VIP may be preferred over PEB to avoid a possible bleomycininduced lung injury in patients with compromised pulmonary function' [2]. Additionally, patients with an extensive disease may benefit from a brief-course or reduced-dose chemotherapy before full-dose chemotherapy is started [2]. Thus, there is an urgent need for clinical research in this field, first in order to better characterize the subgroup of patients that is at risk for the severe complication of a 'tumor-associated' ARDS and second to develop an evidence-based, internationally accepted 'standard-of-care' treatment protocol for those highrisk patients. 


\section{References}

1 Fléchon A, Rivoire M, Droz JP: Management of advanced germ cell tumors of the testis. Nat Clin Pract Urol 2008;5:262-276.

2 Krege S, Beyer J, Souchon R, et al: European consensus conference on diagnosis and treatment of germ cell cancer: a report of the second meeting of the European Germ Cell Cancer Consensus Group (EGCCCG): Part II. Eur Urol 2008;53:497-513.

3 McGowan MP, Pratter MR, Nash G: Primary testicular choriocarcinoma with pulmonary metastasis presenting as ARDS. Chest 1990;97:1258-1259.

4 Moran-Ribon A, Droz JP, Kattan J, Leclercq B, Ghosn M, Couanet D, Ostronoff N, Culine S, Misset B, Escudier B: Super-high-risk germ-cell tumors: a clinical entity. Report of eleven cases. Supp Care Cancer 1994;2:253-258.
5 Kirch C, Blot F, Fizazi K, Raynard B, Theodore C, Nitenberg G: Acute respiratory distress syndrome after chemotherapy for lung metastases from nonseminomatous germ-cell tumors. Supp Care Cancer 2003;11:575-580.

6 Voigt W, Maher G, Wolf HH, Schmoll HJ: Human chorionic gonadotropin-induced hyperthyroidism in germ cell cancer - a case presentation and review of the literature. Onkologie 2007;30:330-334.

7 Gerl A, Lamerz R, Clemm C, Mann K, Hartenstein $\mathrm{R}$, Wilmanns W: Does serum tumor marker halflife complement pretreatment risk stratification in metastatic nonseminomatous germ cell tumors? Clin Cancer Res 1996;2:1565-1570.
8 Pfreundschuh M, Trümper L, Kloess M, Schmits R Feller AC, Rübe C, Rudolph C, Reiser M, Hossfeld DK, Eimermacher H, Hasenclever D, Schmitz N, Loeffler M: Two-weekly or 3-weekly CHOP chemotherapy with or without etoposide for the treatment of elderly patients with aggressive lymphomas: results of the NHL-B2 trial of the DSHNHL. Blood 2004;104:634-641.

9 Fizazi K, Massard C, Postel-Vinay S, Escudier B, Culine S, Raynard B, Blot F, Antoun S, Nitenberg G, Plantade A: Chemotherapy for poor prognosis non seminomatous germ cell tumors (NSGCT): Should doses be reduced at first cycle to prevent acute respiratory distress syndrome (ARDS) in patients with multiple lung metastases? J Clin Oncol 2007;25(18S):abstr 5087. 